\title{
Composição florística da sub-bacia hidrográfica do rio Figueiredo - Ceará - Brasil
}

\author{
Floristic composition of the sub-basin of the Figueiredo river - Ceará - Brazil
}

\author{
SOUSA $^{1}$, L. M.; OLIVEIRA ${ }^{2}$, V. P. V.; BEZERRA ${ }^{3}$, C. L. F.
} losangelaufc@gmail.com

\begin{abstract}
Resumo
A degradação ambiental é um problema sério que acomete os recursos naturais, podendo estar relacionado com as atividades humanas pautadas em práticas inadequadas. $\mathrm{O}$ presente trabalho objetivou realizar uma listagem da composição florística da Sub-bacia hidrográfica do rio Figueiredo para perceber a degradação ambiental a partir da perda da biodiversidade. Os procedimentos metodológicos foram: após a delimitação da sub-bacia e dos seus sistemas ambientais realizou-se a listagem da composição florística com base em trabalhos de campo onde foram aplicadas fichas de campo com auxílio de um mateiro. Para cada sistema foi identificada uma parcela medido 30x30m onde realizou-se a listagem da composição florística. Para a identificação das espécies buscou-se identificar os nomes científicos e suas famílias através de sites especializados e trabalhos publicados (CEARÁ, 2006), (BRASIL, 2012). Os resultados mostraram que a Sub-bacia apresenta composição florística baixa. A maior riqueza florística foi registrada no Maciço do Pereiro e a menor na Planície Fluvial. Das 64 espécies encontradas na área 32 apresentam baixa frequência e apenas 5 alta frequência. Considerando todos os sistemas, verifica-se que o índice de semelhança entre si é baixo, com algumas exceções. Umas das justificativas para tal fato se refere a relação uso/capacidade suporte do ambiente.
\end{abstract}

Palavras-chave: Bacia hidrográfica, degradação ambiental, Riqueza florística.

\begin{abstract}
Environmental degradation is a serious problem that affects natural resources and may be related to human activities based on inadequate practices. The present work aimed to perform a listing of the floristic composition of the sub-basin of Figueiredo river to perceive the environmental degradation from the loss of biodiversity. The methodological procedures were: after the delimitation of the sub-basin and its environmental systems, the floristic composition was made based on fieldwork where field records were applied with the help of a planter. For each system, a 30x30m plot was identified where the floristic composition was listed. For the identification of the species, we sought to identify scientific names and their families through specialized websites and published works (CEARÁ, 2006, BRAZIL, 2012). The results showed that the Subbasin presents low floristic composition. The greatest floristic richness was recorded in the Pereiro Massif and the lowest in the Fluvial Plain. Of the 64 species found in area 32 they present low frequency and only 5 high frequency. Considering all the systems, it is verified that the index of similarity between them is low, with some exceptions. One of the justifications for this fact refers to the relation use/capacity support of the environment.
\end{abstract}

Keywords: Hydrographic basin, environmental degradation, Floristic richness.

\section{INTRODUÇÃO}

O presente artigo tem como objetivo realizar uma listagem da composição florística da Subbacia hidrográfica do rio Figueiredo para perceber a degradação ambiental a partir da perda da biodiversidade. Para tanto, buscou-se relacionar a composição florística com os fatores ecológicos que condicionam a distribuição das espécies nos sistemas ambientais da Sub-bacia.

\footnotetext{
${ }^{1}$ Losângela Martins de Souza, Departamento de Geografia, Universidade do Estado do Rio Grande do Norte, Pau dos Ferros-RN, Brasil. 
A referida área de estudo está localizada na porção Leste do estado do Ceará entre as coordenadas $5^{\circ} 20^{\prime} 00^{\prime \prime}$ e $6^{\circ} 20^{\prime} 00^{\prime \prime} \mathrm{S}$ e $38^{\circ} 00^{\prime} 00^{\prime \prime}$ e $38^{\circ} 40^{\prime} 00^{\prime \prime} \mathrm{W}$. Apresenta-se como o principal afluente da bacia do Médio Jaguaribe pela sua margem direita e limita-se a Norte com a Bacia do Baixo Jaguaribe, ao Sul com o maciço residual do Pereiro, a Oeste com o Riacho do Sangue e a Leste faz divisa com o estado do Rio Grande do Norte. Com 2320 km², a Sub-bacia compreende territórios de seis municípios, são eles: Pereiro, Ererê, Iracema, Potiretama, Alto Santo e São João do Jaguaribe, conforme mostra a Figura 1.

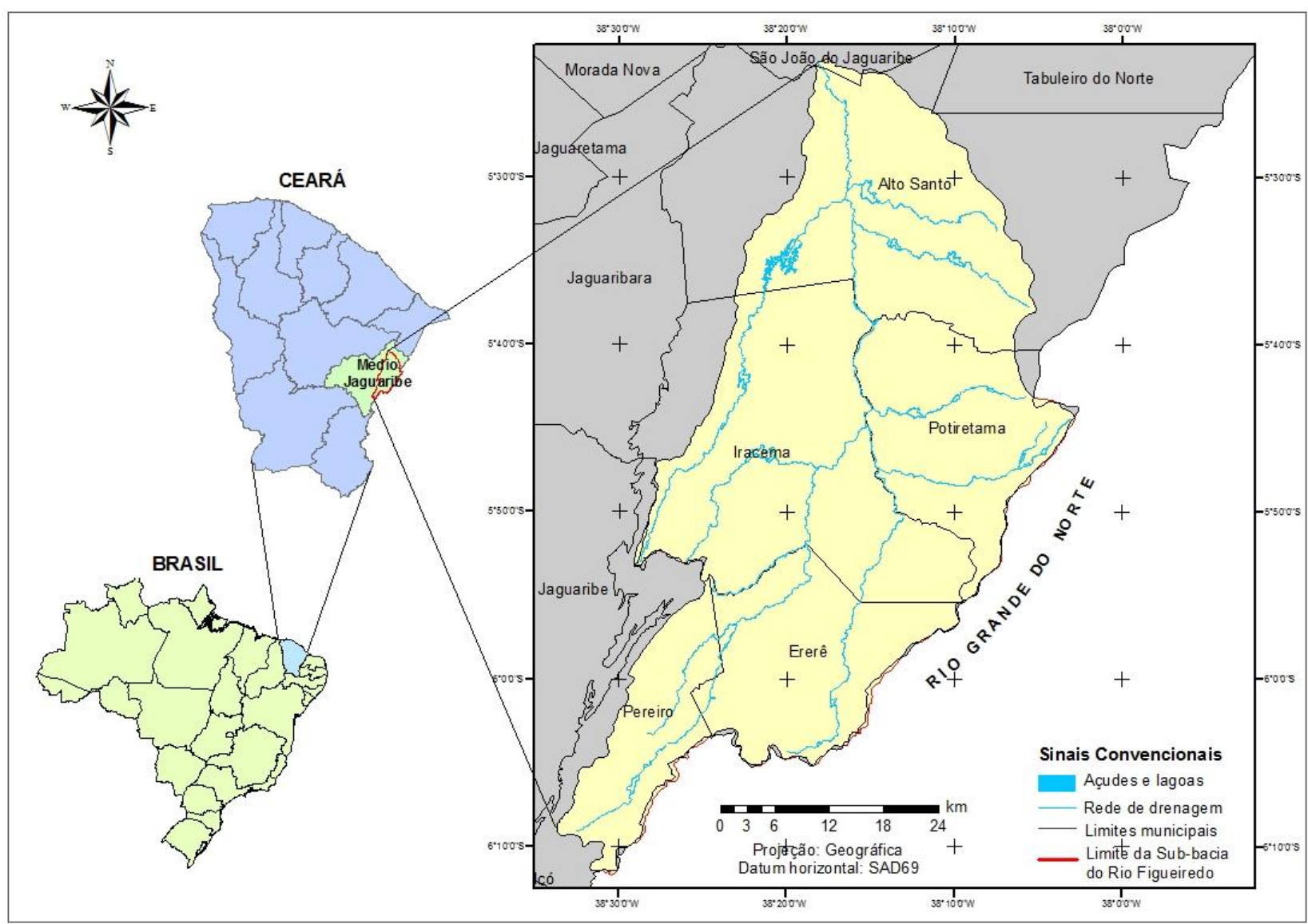

Figura 01. Mapa de localização da sub-bacia hidrográfica do rio Figueiredo. Fonte: Sousa (2012).

De acordo com Sousa (2012) a Sub-bacia hidrográfica do rio Figueiredo possui seis sistemas ambientais. O maciço residual do Pereiro, Sertões de Pereiro/Ererê, Sertões de Iracema/Potiretama, Sertões de Alto Santo, Planície fluvial do rio Figueiredo e superfície de exumação da Formação Açu. Cada sistema ambiental é dotado de condições geoambientais específicas o que implica em potencialidades naturais e limitações de uso. 


\section{METODOLOGIA}

A metodologia utilizada partiu da realização de uma listagem da composição florística de cada sistema ambiental e do seu estado de conservação. Para a identificação da riqueza florística utilizou-se fichas de campo, bem como com ajuda de habitantes locais (mateiros) que auxiliaram nos trabalhos de campo e na identificação das espécies, conforme seu nome popular.

Feita a listagem buscou-se a identificação dos nomes científicos e das famílias de cada espécie através de sites especializados e trabalhos publicados (BRASIL, 2012), (CEARÁ, 2006) e Maia (2004). Para o conhecimento da riqueza florística de cada sistema, ou seja, o número total de espécies identificadas, utilizou-se o método das parcelas, em que para cada sistema ambiental selecionamos uma parcela medindo 30x30m e então realizou-se uma observação em "L" no interior de cada parcela. Dessa forma, considerou-se as espécies localizadas a um metro da linha traçada tanto para a direita quanto para a esquerda. As espécies identificadas pelo mateiro foram registradas na caderneta de campo e posteriormente confrontados com trabalhos científicos já publicados para identificação dos nomes científicos.

Quanto ao estado de conservação da vegetação, o mesmo foi identificado mediante trabalhos de campo, aplicação das fichas, bem como dados coletados sobre a riqueza florística. Com base nos trabalhos de Ceará (2006) a vegetação foi classificada em conservada, parcialmente degradada e degradada. Para tanto, considerou-se a relação entre sistema ambiental, tipologia de usos e riqueza florística.

A frequência das espécies foi realizada mediante cálculo obtido através da regra de três simples em que o total de sistemas ambientais da sub-bacia, (no caso seis) equivale a 100\%, enquanto que o número de sistema que a espécie foi identificada equivale ao número da frequência que se deseja identificar. Um exemplo pode ser verificado com a espécie do cumaru (Myroxylon balsamum). A mesma está presente em quatro sistemas ambientais. Utilizando a regra:

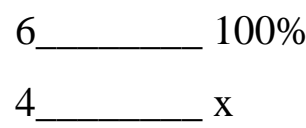

Assim, $x=66,6 \%$, ou seja, o cumaru está frequente em $66,6 \%$ dos sistemas ambientais da Sub-bacia. Com base nos dados referentes à frequência das espécies, foi elaborada uma classe de frequência. A mesma foi identificada conforme a sua ocorrência nos sistemas ambientais. Varia de muito alta, quando está presente de 81 a 100\% dos sistemas a muito baixa, quando está presente de 0 a $20 \%$ dos sistemas, conforme mostra a Tabela 1. 
Tabela 01 - Classe de frequência das espécies conforme a sua ocorrência nos sistemas ambientais Fonte: Sousa (2012).

\begin{tabular}{lr}
\hline \multicolumn{1}{c}{ Classe de frequência das espécies } & \% dos sistemas \\
\hline Muito alta & $81-100$ \\
Alta & $61-80$ \\
Média & $41-60$ \\
Baixa & $21-40$ \\
Muito baixa & $0-20$ \\
\hline
\end{tabular}

A classificação do índice de semelhança florística foi realizada com base no índice de Similaridade (Is) de Sorensen (MULLER-DUMBOIS E ELLENBERG, 1974). Este índice compara duas ou mais amostras e varia de 0 (nenhuma similaridade) a 1 (totalmente similar). Assim, os valores maiores ou iguais a 0,5 indicam semelhanças regular a alta e os valores menores ou iguais a 0,5 pouca semelhança a semelhança inexistente. Os valores são obtidos a partir da equação:

$$
\underline{\mathrm{IS}=2 \mathrm{C} \times 100}
$$

$$
\mathrm{A}+\mathrm{B}
$$

Onde:

$\mathrm{A}=$ total de espécie da comunidade $\mathrm{A}$;

$\mathrm{B}=$ total de espécies da comunidade $\mathrm{B}$ e

$\mathrm{C}=$ total de espécies comuns a A e B.

Com base neste índice foi elaborado o índice de semelhança florística da Sub-bacia do Figueiredo. Desta feita, foram estabelecidos os seguintes intervalos: 0 - 0,2 (Sem Semelhança), 0,21 - 0,4 (Pouca Semelhança), 0,41 - 0,6 (Semelhante), 0,61 - 0,8 (Muito Semelhante) e 0,81-1 (Totalmente Semelhante). Com posse dessas informações foi calculada uma matriz de semelhança florística, tomando como referência os sistemas ambientais identificados.

\section{RESULTADOS E DISCUSSÃO}

A cobertura vegetal original da Sub-bacia hidrográfica do rio Figueiredo, de modo geral, apresenta-se bastante modificada, tanto do ponto de vista florístico quanto estrutural. Uma breve análise da riqueza florística demonstra que seus sistemas ambientais possuem baixo número de espécies. O Quadro 1 mostra a listagem da composição florística, apresentando a família, o nome popular e científico, a presença de cada espécie nos sistemas ambientais e sua frequência em relação a Sub-bacia como um todo. 
Quadro 1. Listagem da riqueza florística da sub-bacia do Rio Figueiredo. Fonte: Sousa (2012).

\begin{tabular}{|c|c|c|c|c|c|c|c|c|c|c|}
\hline $\mathbf{N}^{\mathbf{0}}$ & FAMÍLIA & NOME & NOME & \multicolumn{7}{|c|}{ SISTEMAS AMBIENTAIS } \\
\hline & & & & MP & $\begin{array}{l}\text { SP } \\
\mathbf{E}\end{array}$ & SIP & $\begin{array}{l}\mathbf{S A} \\
\mathbf{S}\end{array}$ & $\mathbf{P A}$ & PF & $\mathbf{F} \%$ \\
\hline 01 & Malvaceae & $\begin{array}{l}\text { Algodão } \\
\text { bravo }\end{array}$ & Pavonia blanchetiana & & $\mathrm{X}$ & & & & & 16,6 \\
\hline 02 & Sabiaceae & $\begin{array}{l}\text { Ameixa/Ame } \\
\text { ixa brava }\end{array}$ & Meliosma itatiaiae & $\mathrm{X}$ & $\mathrm{X}$ & $\bar{X}$ & $\mathrm{X}$ & & & 66,6 \\
\hline 03 & Fabaceae & Angico & Albizia burkartiana & $\mathrm{X}$ & $\mathrm{X}$ & $\mathrm{X}$ & $\mathrm{X}$ & $\mathrm{X}$ & & 83,3 \\
\hline 04 & Fabaceae & Arapiraca & $\begin{array}{l}\text { Chloroleucon } \\
\text { dumosum }\end{array}$ & $\mathrm{X}$ & & & & & & 16,6 \\
\hline 05 & Anacardiaceae & Aroeira & $\begin{array}{l}\text { Apterokarpos } \\
\text { gardneri }\end{array}$ & $\mathrm{X}$ & & & & & & 16,6 \\
\hline 06 & Combretaceae & Bugiu & Combretum laxum & $\mathrm{X}$ & & & & & & 16,6 \\
\hline 07 & Euphorbiaceae & $\begin{array}{l}\text { Burra } \\
\text { leiteira }\end{array}$ & Sapium glandulosum & & & & & $\mathrm{X}$ & $\mathrm{X}$ & 33,3 \\
\hline 08 & Picramniaceae & Café bravo & $\begin{array}{l}\text { Picramnia } \\
\text { glazioviana }\end{array}$ & & & & $\mathrm{X}$ & & & 16,6 \\
\hline 09 & Anacardiaceae & Cajueiro & $\begin{array}{l}\text { Anacardium } \\
\text { occidentale }\end{array}$ & & & & $\mathrm{X}$ & & & 16,6 \\
\hline 10 & Fabaceae & Camará & Cratylia mollis & $\mathrm{X}$ & & $\mathrm{X}$ & $\mathrm{X}$ & & & 50,0 \\
\hline 11 & Fabaceae & Camuzé & $\begin{array}{l}\text { Stryphnodendron } \\
\text { pulcherrimum }\end{array}$ & $\mathrm{X}$ & & & & & & 16,6 \\
\hline 12 & Fabaceae & Canafistula & Senna spectabilis & $\mathrm{X}$ & & & & & & 16,6 \\
\hline 13 & Rubiaceae & $\begin{array}{l}\text { Canela de } \\
\text { veado }\end{array}$ & Alseis latifólia & $\mathrm{X}$ & & & & & & 16,6 \\
\hline 14 & Leguminosae & Capa bode & Bauhinia forficata & $\mathrm{X}$ & & & & & & 16,6 \\
\hline 15 & Cactaceae & Cardeiro & Cereus jamacaru & & & $X$ & $\mathrm{X}$ & & $\mathrm{X}$ & 50,0 \\
\hline 16 & Arecaceae & Carnaúba & Copernicia prunifera & & & & & & $\mathrm{X}$ & 16,6 \\
\hline 17 & Anacardiaceae & Caroba & Schinus lentiscifolius & $\mathrm{X}$ & & & & & & 16,6 \\
\hline 18 & Fabaceae & $\begin{array}{l}\text { Casca } \\
\text { grossa }\end{array}$ & $\begin{array}{l}\text { Platymiscium } \\
\text { pinnatum }\end{array}$ & $\mathrm{X}$ & & & $\mathrm{X}$ & & & 33,3 \\
\hline 19 & Leguminosae & Catanduva & $\begin{array}{l}\text { Piptadenia } \\
\text { moniliformis }\end{array}$ & $\mathrm{X}$ & & & $\mathrm{X}$ & $\mathrm{X}$ & & 50,0 \\
\hline 20 & Apocynaceae & Catingueira & $\begin{array}{l}\text { Aspidosperma } \\
\text { dispermum }\end{array}$ & $\mathrm{X}$ & $\mathrm{X}$ & $\mathrm{X}$ & $\mathrm{X}$ & $\mathrm{X}$ & & 83,3 \\
\hline 21 & Anacardiaceae & Cedro & $\begin{array}{l}\text { Antrocaryon } \\
\text { amazonicum }\end{array}$ & $\mathrm{X}$ & & & & & & 16,6 \\
\hline 22 & Araceae & Cipó preto & $\begin{array}{l}\text { Philodendron } \\
\text { corcovadense }\end{array}$ & $\mathrm{X}$ & & & & & & 16,6 \\
\hline 23 & Connaraceae & $\begin{array}{l}\text { Coração de } \\
\text { negro }\end{array}$ & Connarus suberosus & $\bar{X}$ & & & & & & 16,6 \\
\hline 24 & Fabaceae & Cumarú & Myroxylon balsamum & & $\mathrm{X}$ & $\mathrm{X}$ & $\mathrm{X}$ & $\mathrm{X}$ & & 66,6 \\
\hline 25 & Bombacaceae & Embiratanha & Pachira marginata & $\mathrm{X}$ & & & & & & 16,6 \\
\hline 26 & Cactaceae & Facheiro & Cereus jamacaru & & $\mathrm{X}$ & $\mathrm{X}$ & $\mathrm{X}$ & $\mathrm{X}$ & & 66,6 \\
\hline 27 & Fabaceae & Feijão bravo & Canavalia parviflora & $\mathrm{X}$ & & & & & & 16,6 \\
\hline 28 & Boraginaceae & Frei-jorge & Cordia goeldiana & $\mathrm{X}$ & & & $\mathrm{X}$ & & & 33,3 \\
\hline 29 & Myrtaceae & Goiabinha & $\begin{array}{l}\text { Eugenia } \\
\text { pseudopsidium }\end{array}$ & $\mathrm{X}$ & & & $\mathrm{X}$ & & & 33,3 \\
\hline 30 & Burseraceae & Imburana & $\begin{array}{l}\text { Commiphora } \\
\text { leptophloeos }\end{array}$ & & & & $\mathrm{X}$ & $\mathrm{X}$ & & 33,3 \\
\hline 31 & Moraceae & Inharé & Brosimum guianense & $\mathrm{X}$ & & & & & & 16,6 \\
\hline 32 & Nyctaginaceae & João mole & Guapira SP & $\mathrm{X}$ & & & & & & 16,6 \\
\hline
\end{tabular}

MP: Maciço do Pereiro; SPE: Sertões de Pereiro/Ererê; SIP: Sertões de Iracema/Potiretama; SAS: Sertões de Alto Santo; PA: Patamares do Apodi; PF: Planície Fluvial; F\%: Frequência das espécies. 
Continuação do Quadro 1

\begin{tabular}{|c|c|c|c|c|c|c|c|c|c|c|}
\hline \multirow[t]{3}{*}{$\mathbf{N}^{\mathbf{0}}$} & \multirow[t]{3}{*}{ FAMÍLIA } & \multirow{3}{*}{$\begin{array}{c}\text { NOME } \\
\text { POPULA } \\
\text { R } \\
\end{array}$} & \multirow{3}{*}{$\begin{array}{c}\text { NOME } \\
\text { CIENTÍFICO }\end{array}$} & \multicolumn{7}{|c|}{ SISTEMAS AMBIENTAIS } \\
\hline & & & & & & & & & & \\
\hline & & & & MP & SPE & SIP & SAS & PA & $\mathbf{P F}$ & F\% \\
\hline 33 & Rhamnaceae & Juá & $\begin{array}{l}\text { Ziziphus } \\
\text { cotinifolia }\end{array}$ & $\mathrm{X}$ & $\mathrm{X}$ & $\mathrm{X}$ & & & $\mathrm{X}$ & 66,6 \\
\hline 34 & Leguminosae & Jucá & $\begin{array}{l}\text { Caesalpinia } \\
\text { férrea }\end{array}$ & $\mathrm{X}$ & $\mathrm{X}$ & $\mathrm{X}$ & $\mathrm{X}$ & & & 66,6 \\
\hline 35 & Fabaceae & $\begin{array}{l}\text { Jurema } \\
\text { branca }\end{array}$ & $\begin{array}{l}\text { Chloroleucon } \\
\text { dumosum }\end{array}$ & & $\mathrm{X}$ & $\mathrm{X}$ & $\mathrm{X}$ & & $\mathrm{X}$ & 66,6 \\
\hline 36 & Fabaceae & $\begin{array}{l}\text { Jurema } \\
\text { preta }\end{array}$ & Mimosa tenuiflora & & $\mathrm{X}$ & $\mathrm{X}$ & $\mathrm{X}$ & & & 50,0 \\
\hline 37 & Arecaceae & Macambira & Desmoncus mitis & & & $\mathrm{X}$ & $\mathrm{X}$ & $\mathrm{X}$ & & $\overline{50,0}$ \\
\hline 38 & Euphorbiaceae & Mamaluco & $\begin{array}{l}\text { Caryodendron } \\
\text { amazonicum }\end{array}$ & $\mathrm{X}$ & & & & & & 16,6 \\
\hline 39 & Cactaceae & Mandacaru & Cereus jamacaru & & & $\mathrm{X}$ & $\mathrm{X}$ & $\mathrm{X}$ & $\mathrm{X}$ & 66,6 \\
\hline 40 & Euphorbiaceae & Maniçoba & Manihot glaziovii & $\mathrm{X}$ & & & $\mathrm{X}$ & $\mathrm{X}$ & & $\overline{50,0}$ \\
\hline 41 & Combretaceae & $\begin{array}{l}\text { Marmeleiro } \\
\text { preto }\end{array}$ & $\begin{array}{l}\text { Combretum } \\
\text { leprosum }\end{array}$ & $\mathrm{X}$ & $\mathrm{X}$ & $\mathrm{X}$ & $\mathrm{X}$ & $\mathrm{X}$ & $\mathrm{X}$ & 100 \\
\hline 42 & Euphorbiaceae & $\begin{array}{l}\text { Marmeleiro } \\
\text { branco }\end{array}$ & Croton urticifolius & $\mathrm{X}$ & & & $\mathrm{X}$ & $\mathrm{X}$ & & 50,0 \\
\hline 43 & Combretaceae & Mofumbo & Combretum laxum & & $\mathrm{X}$ & & $\mathrm{X}$ & $\mathrm{X}$ & $\mathrm{X}$ & 66,6 \\
\hline 44 & Fabaceae & Mororó & Bauhinia acreana & $\mathrm{X}$ & & & & $\mathrm{X}$ & & 33,3 \\
\hline 45 & Fabaceae & Mulungu & $\begin{array}{l}\text { Erythrina } \\
\text { amazônica }\end{array}$ & $\mathrm{X}$ & & & & & & 16,6 \\
\hline 46 & Chrysobalanaceae & Murici & Couepia obovata & & & & & & $\mathrm{X}$ & 16,6 \\
\hline 47 & Chrysobalanaceae & Oiticica & Couepia impressa & & $\mathrm{X}$ & & & & $\mathrm{X}$ & 33,3 \\
\hline 48 & Symplocaceae & $\begin{array}{l}\text { Orelha de } \\
\text { onça }\end{array}$ & $\begin{array}{l}\text { Symplocos } \\
\text { estrellensis }\end{array}$ & $\mathrm{X}$ & & & & & & 16,6 \\
\hline 49 & Bixaceae & Pacoté & $\begin{array}{l}\text { Cochlospermum } \\
\text { vitifolium }\end{array}$ & $\mathrm{X}$ & & & $\mathrm{X}$ & $\mathrm{X}$ & & $\overline{50,0}$ \\
\hline 50 & Bignoniaceae & Pau d'arco & $\begin{array}{l}\text { Tabebuia } \\
\text { impetiginosa }\end{array}$ & & $\mathrm{X}$ & $\mathrm{X}$ & $\mathrm{X}$ & & & $\overline{50,0}$ \\
\hline 51 & Rutaceae & Pau branco & $\begin{array}{l}\text { Conchocarpus } \\
\text { grandis }\end{array}$ & & $\mathrm{X}$ & $\mathrm{X}$ & $\mathrm{X}$ & $\mathrm{X}$ & $\mathrm{X}$ & 83,3 \\
\hline 52 & Fabaceae & Pau mocó & $\begin{array}{l}\text { Luetzelburgia } \\
\text { auriculata }\end{array}$ & $\mathrm{X}$ & & & & & & 16,6 \\
\hline 53 & Annonaceae & Pereiro & $\begin{array}{l}\text { Annona } \\
\text { leptopetala }\end{array}$ & $\mathrm{X}$ & $\mathrm{X}$ & $\mathrm{X}$ & $\mathrm{X}$ & & & 66,6 \\
\hline 54 & Euphorbiaceae & $\begin{array}{l}\text { Pinhão } \\
\text { bravo }\end{array}$ & Jatropha curcas & & $\mathrm{X}$ & $\mathrm{X}$ & $\mathrm{X}$ & & $\mathrm{X}$ & $\overline{66,6}$ \\
\hline 55 & Apocynaceae & Pitiá & $\begin{array}{l}\text { Aspidosperma } \\
\text { multiflorum }\end{array}$ & $\mathrm{X}$ & & & & & & 16,6 \\
\hline 56 & Euphorbiaceae & Quebra faca & Croton echioides & $\mathrm{X}$ & & & & & & 16,6 \\
\hline 57 & Apocynaceae & Quina-quina & $\begin{array}{l}\text { Geissospermum } \\
\text { sericeum }\end{array}$ & $\mathrm{X}$ & & & & & & 16,6 \\
\hline 58 & Fabaceae & Sabiá & $\begin{array}{l}\text { Mimosa } \\
\text { caesalpiniifolia }\end{array}$ & $\mathrm{X}$ & $\mathrm{X}$ & $\mathrm{X}$ & $\mathrm{X}$ & $\mathrm{X}$ & & 83,3 \\
\hline 59 & Combretaceae & Sipaúba & $\begin{array}{l}\text { Combretum } \\
\text { monetária }\end{array}$ & $\mathrm{X}$ & & & & & & 16,6 \\
\hline 60 & Fabaceae & Sucupira & $\begin{array}{l}\text { Calliandra } \\
\text { macrocalyx }\end{array}$ & $\mathrm{X}$ & & & & & & 16,6 \\
\hline 61 & Fabaceae & Timbaúba & $\begin{array}{l}\text { Stryphnodendron } \\
\text { pulcherrimum }\end{array}$ & $\mathrm{X}$ & & & & & & 16,6 \\
\hline
\end{tabular}

MP: Maciço do Pereiro; SPE: Sertões de Pereiro/Ererê; SIP: Sertões de Iracema/Potiretama; SAS: Sertões de Alto Santo; PA: Patamares do Apodi; PF: Planície Fluvial; F\%: Frequência das espécies. 
Continuação do Quadro 01.

\begin{tabular}{|l|l|l|l|c|c|c|c|c|c|c|}
\hline $\mathbf{N}^{\mathbf{0}}$ & FAMÍLIA & $\begin{array}{c}\text { NOME } \\
\text { POPULAR }\end{array}$ & $\begin{array}{c}\text { NOME } \\
\text { CIENTÍFICO }\end{array}$ & \multicolumn{6}{|c|}{ SISTEMAS AMBIENTAIS } \\
\hline & & & & MP & SPE & SIP & SAS & PA & PF & F\% \\
\hline 62 & Apocynaceae & Velame & $\begin{array}{l}\text { Mandevilla } \\
\text { pinifolia }\end{array}$ & & & & & & X & 16,6 \\
\hline 63 & Anacardiaceae & Violeta & $\begin{array}{l}\text { Astronium } \\
\text { concinnum }\end{array}$ & X & & & & & & 16,6 \\
\hline 64 & Cactaceae & Xique-Xique & Cereus gounellei & & X & X & X & & & 50,0 \\
\hline & \multicolumn{3}{|c|}{ TOTAL DE ESPÉCIES POR SISTEMA } & 43 & 19 & 20 & 30 & 17 & 13 & \\
\hline
\end{tabular}

MP: Maciço do Pereiro; SPE: Sertões de Pereiro/Ererê; SIP: Sertões de Iracema/Potiretama; SAS: Sertões de Alto Santo; PA: Patamares do Apodi; PF: Planície Fluvial; F\%: Frequência das espécies.

O Maciço Residual do Pereiro na sua porção pertencente à Sub-bacia estudada possui aproximadamente $450 \mathrm{~km}^{2}$ e apresenta a maior riqueza florística da bacia, totalizando 43 espécies. A Planície Fluvial abrange aproximadamente $30 \mathrm{~km}^{2}$ e possui a menor riqueza florística, com apenas 13 espécies. Os Sertões compreendem as maiores áreas da Sub-bacia variando entre 500 e $600 \mathrm{~km}^{2}$ e apresentam riqueza intermediária, variando entre 19 até 30 espécies.

Tabela 02. Riqueza florística dos sistemas ambientais da Sub-bacia do Figueiredo. Fonte: Sousa (2012).

\begin{tabular}{l|r|r}
\hline \multicolumn{1}{c|}{ SISTEMA AMBIENTAL } & $\begin{array}{c}\text { ÁREA } \\
\left(\mathbf{K M}^{\mathbf{2}}\right)\end{array}$ & $\begin{array}{c}\text { RIQUEZA FLORÍSTICA } \\
\left(\mathbf{N}^{\mathbf{0}} \text { DE ESPÉCIES) }\right.\end{array}$ \\
\hline Maciço Residual do Pereiro & 450 & 43 \\
Planícies Fluviais & 30 & 13 \\
Sertões de Alto Santo & 600 & 30 \\
Sertões de Iracema/Potiretama & 500 & 20 \\
Sertões de Pereiro/Ererê & 590 & 19 \\
Superfície de exumação da Formação & & 17 \\
Açu & 150 & \\
TOTAL & 2320 & \\
\hline
\end{tabular}

Tomando como referência o Maciço do Pereiro e as Planícies Fluviais, percebe-se que riqueza florística é bastante diferente. Enquanto no Maciço encontrou-se mais de 40 espécies na Planície esse número diminuiu para 13. A justificativa para tal fato é complexa, porém, alguns fatores ecológicos podem contribuir significativamente para tal distribuição. Melhores condições de umidade e solos profundos ricos em argila, no caso os Argissolos, associado ao relevo mais dissecado no Maciço podem ajudar na melhor conservação da cobertura vegetal. No caso das Planícies fluviais os fatores ecológicos como hidrografia, relevo e condições microclimáticas são de suma importância para garantir o equilíbrio dos ecossistemas, porém a intensidade dos usos geram fortes impactos e consequentemente diminuição da riqueza florística deste sistema ambiental. 
Ao fazermos uma relação entre riqueza florística e área $\left(\mathrm{km}^{2}\right)$, verifica-se que os Sertões apresentam aspectos de degradação mais avançados pois, possuem maiores áreas e baixa riqueza florística. As planícies fluviais embora muito degradadas e com uma riqueza florística baixa apresentam, nessa relação, as melhores condições ambientais pois, em $30 \mathrm{~km}^{2}$ verificou-se 13 espécies, aspecto este, que pode ser justificado pelos fatores ecológicos presentes nas Planícies.

Enquanto no Maciço as práticas estão voltadas ao extrativismo vegetal, fruticultura, atividade agrícola e pecuária, proporcionando alteração na arquitetura das copas das árvores, espaçamento do estrato arbóreo e presença mais frequente de arbustos, nas Planícies Fluviais, a degradação, fica por conta da forte pressão que esta área sofre diante da ocupação urbana, ocupação inadequada do leito maior do rio Figueiredo, contribuindo para o assoreamento dos canais e alargamento dos vales.

A diferença da riqueza florística entre esses sistemas pode ser justificada pela relação entre a capacidade de suporte e a tipologia de usos destes ambientes. Assim, pode-se atribuir a maior riqueza de espécies no Maciço do Pereiro às suas boas condições de solo e maior umidade em relação ao restante da Sub-bacia. Ali chove em média $800 \mathrm{~mm} /$ ano enquanto que no restante da subbacia esta média varia entre 550 e $600 \mathrm{~mm}$ aproximadamente (SOUSA, 2012). As planícies Fluviais, embora possuam umidade e solos férteis, sofrem pressões advinda das atividades humanas, a utilização intensiva desse sistema ambiental torna-o mais vulnerável.

As principais causas da degradação ambiental nas Planícies Fluviais do rio Figueiredo se referem às práticas inadequadas da agricultura e pecuária, através de queimadas, desmatamento para produção de lenha e pastagem para o rebanho. Além do extrativismo vegetal descontrolado a ocupação das áreas ribeirinhas descumprem a legislação ambiental a partir da ocupação das Áreas de Proteção Permanente (APPs), sem o devido respeito aos limites previstos no Código Florestal (Lei 12.651/2012).

Os sertões apresentam-se fortemente degradados, com riqueza florística baixa, variando entre 19 e 30 espécies. A cobertura vegetal original está bastante descaracterizada, há predominância de solos desnudos e arbustos variados. Como as principais atividades econômicas são a pecuária extensiva e a agricultura tradicional, ocorre à retirada da cobertura original para possibilitar as pastagens, assim como para obtenção de lenha e madeira. Tais práticas contribuem significativamente para diminuir a riqueza florística dos Sertões e aumentar a frequência e abundância de espécies, como acontece com o Xiquexique (Cereus gounellei), e outras indicadoras com fenótipo adaptativo as condições xéricas do ambiente.

Mesmo apresentando sinais de avançados processos de degradação ambiental, a riqueza florística dos sertões da Sub-bacia hidrográfica do Figueiredo é superior às Planícies Fluviais e a 
Superfície de Exumação da Formação Açu. Um dos fatores que contribuem para justificar tal situação é a diversidade das espécies da Caatinga e sua excelente capacidade de adaptação às condições adversas. Esta capacidade se dá através das suas características peculiares de adaptação à semiaridez, como cascas claras, folhas pequenas, e textura que lembra couro, perda das folhas no período seco, sementes leves, armazenamento de água no caule, na parte verde, como as cactáceas, ou nas raízes, como o umbuzeiro (Spondias tuberosa) e o pacoté (Cochospermum vitifolium).

A baixa riqueza de espécies da Superfície de Exumação da Formação Açu se dá especialmente pela retirada da vegetação original e predomínio do agroextrativismo, com o cultivo do Cajueiro (Anarcadium occidentale), agricultura de subsistência e pastagens. Em virtude da alta frequência do Cajueiro neste sistema, optou-se por incluí-lo na composição florística, embora esta espécie não seja nativa, mas introduzida.

O Quadro 02 exibe a relação sistema ambiental/uso da terra/riqueza florística. Desta feita, constata-se que as formas de uso da terra, como agricultura, pecuária e extrativismo são comuns nos sistemas ambientais da área estudada. No entanto, a riqueza florística é bastante diferente. Isso pode ser justificado pelas condições naturais de cada sistema, o que indica que a capacidade de suporte de cada um, é diferenciada diante de práticas desenvolvidas.

Quadro 02. Relação entre sistema ambiental, uso/ocupação e riqueza florística. Fonte: Sousa (2012).

\begin{tabular}{|l|l|r|}
\hline \multicolumn{1}{|c|}{ SISTEMA AMBIENTAL } & \multicolumn{1}{|c|}{ USO/OCUPAÇÃo } & \multicolumn{1}{|c|}{$\begin{array}{c}\text { RIQUEZA } \\
\text { FLORÍSTICA } \\
\text { (No DE ESPÉCIES) }\end{array}$} \\
\hline Maciço residual do Pereiro & $\begin{array}{l}\text { Agricultura de subsistência, pecuária, } \\
\text { extrativismo vegetal, ocupação urbana, } \\
\text { fruticultura. }\end{array}$ & 43 \\
\hline $\begin{array}{l}\text { Sertões de Pereiro/Ererê, } \\
\text { Iracema/Potiretama, } \\
\text { Alto Santo }\end{array}$ & $\begin{array}{l}\text { Agropecuária, agricultura de subsistência, } \\
\text { extrativismo vegetal, pastagens, apicultura. }\end{array}$ & 19 \\
\hline $\begin{array}{l}\text { Superfície de Exumação da } \\
\text { Formação Açu }\end{array}$ & $\begin{array}{l}\text { Agropecuária, agroextrativismo (cajueiro), } \\
\text { Cultivo de algodão, apicultura. }\end{array}$ & 30 \\
\hline Planície fluvial & $\begin{array}{l}\text { Extrativismo vegetal (carnaúbas), agricultura de } \\
\text { subsistência e irrigada, pesca artesanal, pecuária, } \\
\text { ocupação urbana, indústria ceramista, mineração. }\end{array}$ & 17 \\
\hline
\end{tabular}

De acordo com o Quadro 02, percebe-se que, quanto mais variada a tipologia de uso, maior é a possibilidade da redução da riqueza florística. O que indica que os usos inadequados contribuem para depauperar a vegetação original, comprometendo o equilíbrio natural dos sistemas ambientais em foco.

Deste modo, a caatinga é de fundamental importância para o equilíbrio dos sertões, pois fornece produtos para o consumo, comércio e indústria, como frutos, madeira, mel de abelha, 
higiene corporal e substâncias para tintas e fibras. É importante também para a proteção dos solos contra erosão, na sua fertilidade, bem como na conservação da água e no controle de pragas (MAIA, 2004).

No que se refere à frequência de espécies da Sub-bacia, a mesma foi dividida em classes, conforme a sua presença nos sistemas ambientais. As classes variam de muito alta, quando a espécie está presente de 81 a 100\% dos sistemas, à muito baixa, quando a espécie está presente em até $20 \%$ dos sistemas, conforme mostra a Tabela 01, já apresentada.

Tomando como referência as principais espécies identificadas nos sistemas da Sub-bacia, verifica-se que das 64 espécies 5 delas apresentam frequência muito alta, 10 frequência Alta, 10 frequência média, 7 baixa e 32 muito baixa, conforme o Quadro 03.

Quadro 03 - Distribuição das espécies vegetais por classes de frequências. Fonte: Sousa (2012).

\begin{tabular}{|l|r|r|l|}
\hline $\begin{array}{c}\text { CLASSE DE } \\
\text { FREQUÊNCIA } \\
\text { DAS } \\
\text { ESPÉCIES }\end{array}$ & $\begin{array}{c}\text { \% DOS } \\
\text { SISTEMAS }\end{array}$ & $\begin{array}{c}\mathbf{N}^{\mathbf{0}} \text { DE } \\
\text { ESPÉCIES }\end{array}$ & \multicolumn{1}{|c|}{ NOME DAS ESPÉCIES } \\
\hline Muito alta & $81-100$ & 5 & $\begin{array}{l}\text { Marmeleiro preto, Angico, Sabiá, Pau branco, } \\
\text { Catingueira, }\end{array}$ \\
\hline Alta & $61-80$ & 10 & $\begin{array}{l}\text { Ameixa, Pinhão bravo, Pereiro, Mofumbo, Mandacarú, } \\
\text { Juazeiro, Jucazeiro, Jurema branca, Facheiro, Cumaru, }\end{array}$ \\
\hline Média & $41-60$ & 10 & $\begin{array}{l}\text { Camará, Cardeiro, Catanduva, jurema preta, macambira, } \\
\text { maniçoba, Marmeleiro branco, Pacoté, paud'arco, } \\
\text { xique-xique, }\end{array}$ \\
\hline Baixa & $21-40$ & 7 & $\begin{array}{l}\text { Burra Leiteira, Casca grossa, Frei-jorge, Goiabinha, } \\
\text { Imburana, Mororó, Oiticica }\end{array}$ \\
\hline Muito baixa & $0-20$ & 32 & $\begin{array}{l}\text { Algodão-bravo, Arapiraca, Aroeira, Bugiu, Café-bravo, } \\
\text { Cajueiro, Camuzé, Canafístula, Canela-de-veado, Capa- } \\
\text { bode, Carnaúba, Caroba, Cedro, Cipó-preto, Coração- } \\
\text { de-negro, Embiratanha, Feijão-bravo, Inharé, João- } \\
\text { mole, mamaluco, Mulungú, Murici, Orelha-de-onça, } \\
\text { mau-mocó, Pitiá, Quebra-faca, Quina-quina, Sipaúba, } \\
\text { Sucupira, Timbaúba, velame, Violeta. }\end{array}$ \\
\hline Total de espécies & & 64 & \begin{tabular}{l} 
\\
\hline
\end{tabular} \\
\hline
\end{tabular}

Destas, se verifica que o Marmeleiro preto com 100\% de frequência, seguida pelo Angico, Catingueira, Pau branco e Sabiá com 83,3\%. Estas espécies da caatinga são de grande importância servindo especialmente para madeira, alimentação humana, medicina caseira, restauração florestal, forragem, e apicultura.

Vale ressaltar que o Marmeleiro preto possui certa capacidade de se sobressair às demais por ser pouco exigente em solo e água e, portanto, se propaga com maior facilidade, diante das condições adversas do meio, ou seja, em áreas degradadas. 
De acordo com Quadro 03, acima, entre as espécies que apresentam alta frequência estão o Facheiro, Mandacarú e Jurema branca. Assim como o Marmeleiro preto, estas espécies conseguem se adaptar as condições de degradação e retirar dos solos as condições necessárias ao seu desenvolvimento, mesmo estando inseridas em áreas extremamente degradadas. As espécies da família das Cactaceae também são possuidoras de tal habilidade, em função da capacidade de retenção de água. Inclusive, algumas delas como o Mandacarú e Xiquexique são bastante utilizadas durante os períodos de secas na alimentação dos rebanhos.

As espécies com frequência média são aquelas pouco exigentes, como a Macambira, Xiquexique, Cardeiro, Marmeleiro branco e Jurema preta. Estas espécies são facilmente encontradas nas áreas degradadas.

A maioria das espécies, ou seja, 32, apresenta frequência muito baixa, o que corresponde $(16,6 \%)$ do total de espécies identificadas na Sub-bacia. A maioria delas está presente no Maciço Residual do Pereiro, que, mesmo degradado, possui condições ecológicas para o desenvolvimento mais favorável destas espécies, frente aos Sertões.

O levantamento da composição florística da Sub-bacia foi suficiente para se verificar que as espécies como a Imburana, Mororó, Frei-jorge e Canafístula possuem frequência variando de baixa a muito baixa, o que pode trazer grandes prejuízos à estrutura das comunidades nativas. Estas espécies são de vasta utilidade, especialmente madeira, medicina caseira, nas primeiras fases da restauração florestal de áreas degradadas, apicultura e forragem (MAIA, 2004).

Tais dados revelam as fortes alterações que vêm ocorrendo na Sub-bacia do Figueiredo, não apenas da cobertura vegetal, mas também indicam evidências dos processos erosivos, exposição de solos, aumento dos pavimentos desérticos e presença de afloramentos rochosos. Esta realidade possibilita a análise da relação entre a degradação ambiental/desertificação e as formas de uso e ocupação da terra.

A Tabela 03 apresenta a classificação do índice de semelhança florística. Este índice varia de 0 a 1 , sendo 0 , sem semelhança e 1 totalmente semelhante (MUELLER-DUMBOIS e ELLENBERG, 1974).

Tabela 03. Índice de Semelhança Florística Fonte: Elaborado pelo autor, com base em Mueller-Dumbois e Ellenberg (1974).

\begin{tabular}{lr}
\hline \multicolumn{1}{c|}{ Classe de Semelhança } & \multicolumn{1}{c}{ Índice } \\
\hline Sem semelhança & $0-0,2$ \\
Pouca semelhança & $0,21-0,4$ \\
Semelhante & $0,41-0,6$ \\
Muito semelhante & $0,61-0,8$ \\
Totalmente semelhante & $0,81-1$ \\
\hline
\end{tabular}


De acordo com esta classificação, e com base no levantamento florístico da área pesquisada, foi elaborada a matriz de semelhança florística entre os sistemas ambientais da Sub-bacia, como mostra o Quadro 04.

Quadro 04. Matriz de semelhança florística entre os sistemas ambientais da sub-bacia do Figueiredo. Fonte: Sousa (2012).

\begin{tabular}{|l|l|l|l|l|l|l|}
\hline & $\begin{array}{l}\text { Maciço } \\
\text { Residual } \\
\text { do Pereiro }\end{array}$ & $\begin{array}{l}\text { Sertões } \\
\text { Pereiro/ } \\
\text { Ererê }\end{array}$ & $\begin{array}{l}\text { Sertões } \\
\text { Iracema/ } \\
\text { Potiretama }\end{array}$ & $\begin{array}{l}\text { Sertões de } \\
\text { Alto Santo }\end{array}$ & $\begin{array}{l}\text { Superfície de } \\
\text { exumação do do decú } \\
\text { Formação Açu }\end{array}$ & $\begin{array}{l}\text { Planie } \\
\text { Fluvial }\end{array}$ \\
\hline $\begin{array}{l}\text { Maciço } \\
\text { residual do } \\
\text { Pereiro }\end{array}$ & - & 0,25 & 0,27 & 0,32 & 0,26 & 0,07 \\
\hline $\begin{array}{l}\text { Sertões de } \\
\text { Pereiro/Ererê }\end{array}$ & - & - & 0,82 & 0,60 & 0,43 & 0,37 \\
\hline $\begin{array}{l}\text { Sertões de } \\
\text { Iracema } \\
\text { Potiretama }\end{array}$ & - & - & - & 0,74 & 0,47 & 0,42 \\
\hline $\begin{array}{l}\text { Sertões de } \\
\text { Alto Santo }\end{array}$ & - & - & - & - & 0,63 & 0,33 \\
\hline $\begin{array}{l}\text { Superfície de } \\
\text { exumação da } \\
\text { Formação } \\
\text { Açu }\end{array}$ & - & - & - & - & - & 0,27 \\
\hline $\begin{array}{l}\text { Planície } \\
\text { fluvial }\end{array}$ & - & - & - & - & - & - \\
\hline
\end{tabular}

Com base na matriz, observa-se que o Maciço do Pereiro apresenta-se sem semelhança em relação à Planície Fluvial, com índice igual a 0,07, e com pouca semelhança em relação aos Sertões de Alto Santo, com índice de 0,32. Este dado mostra que o maciço possui maior capacidade de suporte em relação às planícies por apresentar condições naturais mais favoráveis.

Os Sertões de Pereiro/Ererê se apresentam totalmente semelhante aos de Iracema/Potiretama $(0,82)$, pouco semelhante aos de Alto Santo e a Superfície de Exumação $(0,60$ e 0,43, respectivamente) e pouca semelhança em relação às Planícies Fluviais (0,37). Pode-se atribuir a semelhança florística entre os sertões pelas potencialidades e limitações que estes possuem, bem como pelos processos de usos também semelhantes. Assim, os sertões possuem condições naturais agressivas, alta capacidade de resiliência das caatingas e formas de usos semelhantes, o que pode tornar estes ambientes relativamente parecidos.

A Superfície de exumação apresenta-se semelhante aos sertões, especialmente de Alto Santo. A justificativa para tal fato se dá por ser uma área submetida às mesmas condições de semiaridez dos sertões e por possuir igual processo de ocupação, pautado em práticas rudimentares 
que contribuíram para depredar a biodiversidade. Assim, a substituição da cobertura vegetal original pelo cultivo do Cajueiro possibilitou a diminuição considerável da riqueza florística desta unidade ambiental.

As Planícies fluviais apresentam índice de semelhança florística variando de 0,07 em relação ao Maciço do Pereiro, à 0,42, em relação aos Sertões de Iracema/Potiretama. Entre as razões da pouca semelhança, podem-se destacar as formas de ocupação da área. Os baixos vales fluviais vêm sendo cada vez mais ocupados pelas atividades rurais e urbanas, contribuindo para descaracterizar aquela paisagem.

Considerando todos os sistemas, verifica-se que o índice de semelhança entre si é baixo, com algumas exceções. Umas das justificativas para tal fato se refere a relação uso/capacidade suporte do ambiente. De tal modo que o ambiente dá respostas diferenciadas frentes os usos. Estes podem apresentar respostas diferenciadas ao ambiente diante das suas potencialidades e limitações.

O Quadro 05 apresenta uma síntese dos principais problemas desencadeados pelos diversos usos da Sub-bacia, bem como as principais diretrizes na busca de minimizar tais efeitos.

Quadro 05. Síntese dos problemas da Sub-bacia do Figueiredo e diretrizes ambientais. Fonte: Sousa (2012).

\begin{tabular}{|c|c|c|c|}
\hline $\begin{array}{c}\text { Sistema } \\
\text { Ambiental }\end{array}$ & $\begin{array}{c}\text { Tipologia de } \\
\text { uso/ocupação }\end{array}$ & Problemas configurados & $\begin{array}{c}\text { Diretrizes } \\
\text { Ambientais }\end{array}$ \\
\hline $\begin{array}{l}\text { Maciço } \\
\text { residual do } \\
\text { Pereiro }\end{array}$ & $\begin{array}{lr}\text { Agricultura } & \text { de } \\
\text { subsistência, } & \text { pecuária, } \\
\text { extrativismo } & \text { vegetal, } \\
\text { ocupação } & \text { urbana, } \\
\text { fruticultura. } & \end{array}$ & $\begin{array}{l}\text { Perda da biodiversidade, } \\
\text { erosão dos solos, } \\
\text { Poluição dos recursos } \\
\text { hídricos, cultivo nas } \\
\text { vertentes íngrimes, } \\
\text { Descumprimento } \\
\text { legislação ambiental da }\end{array}$ & $\begin{array}{l}\text { Manutenção dos sistemas, } \\
\text { Proteção dos mananciais, } \\
\text { controle da degradação, práticas } \\
\text { de conservação dos solos e dos } \\
\text { recursos naturais, práticas de } \\
\text { educação ambiental }\end{array}$ \\
\hline $\begin{array}{l}\text { Sertões de } \\
\text { Pereiro/Ererê, } \\
\text { Iracema/ } \\
\text { Potiretama } \\
\text { Alto Santo }\end{array}$ & $\begin{array}{l}\text { Agropecuária, } \\
\text { agricultura de } \\
\text { subsistência, } \\
\text { extrativismo vegetal, } \\
\text { pastagens, apicultura. }\end{array}$ & $\begin{array}{lr}\text { Aumento das } & \text { áreas } \\
\text { susceptíveis } & \text { à } \\
\text { desertificação, erosão } & \mathrm{e} \\
\text { empobrecimento } & \text { dos } \\
\text { solos, perda } & \text { da } \\
\text { biodiversidade. } & \\
\end{array}$ & 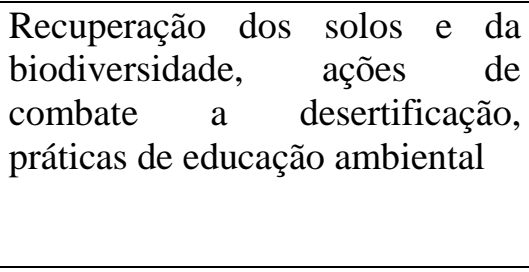 \\
\hline $\begin{array}{l}\text { Superfície de } \\
\text { exumação da } \\
\text { Formação } \\
\text { Açu }\end{array}$ & $\begin{array}{l}\text { Agropecuária, } \\
\text { agroextrativismo } \\
\text { (cajueiro), Cultivo de } \\
\text { algodão, apicultura. }\end{array}$ & $\begin{array}{l}\text { Perda da biodiversidade, } \\
\text { erosão dos solos, } \\
\text { Descumprimento } \\
\text { legislação ambiental. }\end{array}$ & $\begin{array}{l}\text { Controle da degradação, práticas } \\
\text { de conservação dos solos e dos } \\
\text { recursos naturais, educação } \\
\text { ambiental. }\end{array}$ \\
\hline $\begin{array}{l}\text { Planície } \\
\text { fluvial }\end{array}$ & 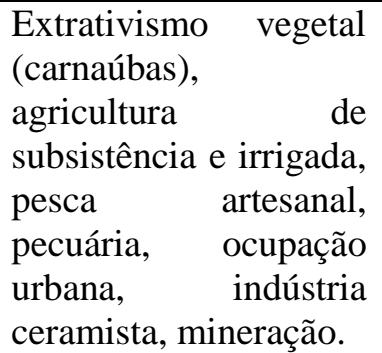 & $\begin{array}{l}\text { Perda da biodiversidade, } \\
\text { assoreamentos dos canais, } \\
\text { degradação da mata ciliar, } \\
\text { descumprimento da } \\
\text { legislação ambiental. }\end{array}$ & $\begin{array}{l}\text { Práticas de educação ambiental e } \\
\text { cumprimento da legislação, } \\
\text { Recuperação da mata ciliar. } \\
\text { Mineração controlada. }\end{array}$ \\
\hline
\end{tabular}


Desta feita, verifica-se que os problemas são semelhantes nos sistemas da sub-bacia. Destaca-se, porém, perda da biodiversidade, erosão dos solos, descumprimento da legislação ambiental e susceptibilidade aos processos de desertificação função da degradação ambiental avançada. Problemas estes que interfere na qualidade de vida das populações que, em maioria, apresenta índices altos de pobreza.

Em virtude disso, se faz necessário o apontamento de diretrizes ambientais, entre elas podem-se mencionar as práticas de educação ambiental, recuperação dos solos e da biodiversidade, reflorestamento, cumprimento da legislação ambiental, bem como ações de combate à desertificação.

Diante deste panorama, verifica-se que a degradação ambiental está se apresentando de forma acentuda na sub-bacia, o que necessita de prática de controle para evitar que maiores problemas sejam desencadeados como a desertificação.

Deste modo, justifica-se a necessidade da gestão adequada dos recursos naturais, possibilitando o desenvolvimento com base em três setores principais, quais sejam: o social, o ambiental e o econômico, na perspectiva de garantir melhorias de condições de vida das populações e um maior equilíbrio dos ecossistemas semiáridos da área estudada.

\section{CONSIDERAÇÕES FINAIS}

A Sub-bacia hidrográfica do rio Figueiredo apresenta-se como uma área de grande significado para os estudos florísticos da caatinga, pois possui diversos sistemas ambientais e aspectos de degradação avançados.

Desta feita, foram encontradas 64 espécies na composição florística total da Sub-bacia. Destas, as cinco espécies mais frequentes são o Marmeleiro preto, Angico, Sabiá, Pau branco, Catingueira. Dentre as espécies menos frequentes podemos citar o Algodão-bravo, Arapiraca, Aroeira, Canafístula, Caroba, Cedro, Murici, Sucupira, Timbaúba, entre outras.

O estudo mostrou que o sistema ambiental de maior riqueza florística é o Maciço Residual do Pereiro e o sistema de menor riqueza são as Planícies Fluviais. Os Sertões de Alto Santo, Sertões de Iracema/Potiretama e Sertões de Pereiro/Ererê apresentam a segunda, terceira e quarta maior riqueza florística da Sub-bacia, respectivamente. Porém, são os sistemas ambientais mais degradados da bacia. Ocupam juntos cerca de $1690 \mathrm{~km}^{2}$ e foram registradas apenas 32 espécies vegetais.

De modo geral verifica-se que os sertões apresentam semelhança florística alta, enquanto que a menor semelhança está entre o Maciço do Pereiro e a Planície Fluvial. 
O presente estudo também deu conta de que os sistemas ambientais do Figueiredo possuem problemas ambientais configurados pelos tipos de uso e ocupação ali desenvolvidos, o que exige diretrizes ambientais no sentido de desenvolver práticas de planejamento e ordenamento territorial.

\section{REFERÊNCIAS}

BRASIL. Banco do Nordeste do Brasil. Plantas do Nordeste, especialmente do Ceará. Vingt UnRosado e América Rosado. Acervo virtual Osvaldo Lamartine de Faria. Coleção Mossoense. (www.colecaomossoroense.org.br), acessado em 25/01/12.

CEARÁ. Fundação Cearense de Meteorologia e Recursos Hídricos. Mapeamento da cobertura vegetal e do uso/ocupação do solo da APA da serra de Baturité - Ceará. Fortaleza, 2006.

MAIA, G. N. Caatinga: Árvores e Arbustos e suas utilidades. 1 ed. São Paulo: D\&Z Computação Gráfica e Editora, 2004.

MUELLER-DUMBOIS, D e H. ELLENBERG - Aims and Methods in Vegetation Ecology - John Wiley \& Sons, N. York, 1974.

SOUSA, M. L. M. de. Diagnóstico Geoambiental da Sub-Bacia Hidrográfica do Rio Figueiredo, Ceará: Subsídios ao Planejamento Ambiental. Dissertação de Mestrado apresentado ao Programa de Pós-Graduação em Geografia da Universidade Federal do Ceará, Fortaleza, 2012. $144 \mathrm{p}$.

\section{AGRADECIMENTOS}

Agradeço ao Programa de Pós-graduação da Universidade Federal do Ceará - UFC, pela oportunidade de desenvolver a dissertação de mestrado intitulada: Diagnóstico Geoambiental da sub-bacia hidrográfica do rio Figueiredo, Ceará: subsídios ao planejamento ambiental, a qual este trabalho faz parte. Agradecer também a Fundação Cearense de Apoio ao Desenvolvimento Científico e Tecnológico - FUNCAP pelo financiamento da pesquisa. Os agradecimentos se estendem à professora Dra. Vládia Pinto Vidal de Oliveira (orientadora) e ao Prof. Carlos Lineu Frota Bezerra pelas preciosas contribuições.

Recebido em: 15/08/2018

Aceite para publicação em: 05/11/2018 